\section{Factores socioeconómicos y clínicos asociados con infecciones oportunistas en pacientes con HIV afiliados al sistema de salud}

\author{
Mónica María Lopera1, Yesly Lemos² \\ ${ }^{1}$ Línea de Investigación en Sistemas de Salud, Grupo de Gestión y Políticas de Salud, Facultad \\ Nacional de Salud Pública, Universidad de Antioquia, Medellín, Colombia \\ ${ }^{2}$ Semillero de Investigación SISALUD, Facultad Nacional de Salud Pública, Universidad de \\ Antioquia, Medellín, Colombia
}

Introducción. A pesar de los avances clínicos, las infecciones oportunistas son la principal causa de morbimortalidad en pacientes con el virus de la inmunodeficiencia humana (HIV). Objetivos. Estimar la prevalencia de las infecciones oportunistas en pacientes con HIV afiliados al sistema de salud, y establecer su asociación con factores sociodemográficos y clínicos. Materiales y métodos. Se hizo un estudio observacional con enfoque analítico. Se analizaron 37.325 registros de personas con HIV afiliadas al sistema de salud. Se hizo el análisis bivariado usando las pruebas de ji al cuadrado y de varianza (ANOVA) ajustadas por Bonferroni y una regresión logística múltiple para la población adulta, con el fin de establecer la asociación entre los factores sociodemográficos y clínicos, y la presencia, por lo menos, de una infección oportunista como variable de respuesta.

Resultados. El $18 \%$ de las personas había tenido, por lo menos, una infección oportunista. Las más frecuentes en adultos fueron la tuberculosis y la toxoplasmosis cerebral, y en menores de 13 años, las neumonías y las diarreas. La prevalencia fue significativamente mayor en hombres $\left(O R=1,5 ; I C_{95 \%} 1,4-1,6\right)$, en mayores de 40 años $\left(\mathrm{OR}=1,6 ; \mathrm{IC}_{95 \%} 1,3-2,0\right)$, en desplazados $\left(\mathrm{OR}=1,7 ; \mathrm{IC}_{95 \%} 1,5-1,9\right)$ y en afiliados al régimen subsidiado y de excepción (OR=2,7; IC $\left.{ }_{95 \%} 2,1-3,4\right)$. En cuanto a los factores clínicos, la asociación fue significativa en pacientes diagnosticados más de diez años atrás $(O R=1,6$; $\left.\mathrm{IC}_{95} 1,5-1,7\right)$ y en aquellos con tratamiento antirretroviral $\left(\mathrm{OR}=4,4 ; \mathrm{IC}_{95 \%} 3,9-5,1\right) \mathrm{O}$ discontinuidad en el tratamiento $\left(\mathrm{OR}=1,7 ; \mathrm{IC}_{95} 1,6-1,8\right)$. El análisis multivariado se hizo en adultos en estadio $A$ de la infección, con resultados similares.

Conclusiones. A pesar de la naturaleza prevenible de las infecciones oportunistas, su prevalencia fue alta y afectó predominantemente a los grupos más desfavorecidos de la sociedad.

Palabras clave: infecciones oportunistas/epidemiología; infecciones por $\mathrm{VIH}$; factores socioeconómicos; disparidades en el estado de salud; sistemas de salud.

Recibido: $21 / 05 / 18$

Aceptado: 03/09/18

Publicado: $11 / 09 / 18$

Citación:

Lopera MM, Lemos Y. Factores socioeconómicos y clínicos asociados con infecciones oportunistas en pacientes con HIV afiliados al sistema de salud. Biomédica. 2019;39:186-204

https://doi.org/10.7705/biomedica.v39i2.4508

\section{Correspondencia:}

Mónica María Lopera, Calle $62 \mathrm{~N}^{\circ} 52-59$, bloque 33, oficina 413, Universidad de Antioquia, Medellín, Colombia

Teléfono: (574) 219 6845; fax: (574) 2191017

monica.lopera@udea.edu.co

Contribución de los autores:

Las dos autoras participaron en la concepción y el diseño del estudio, el análisis e interpretación de los datos, la búsqueda y revisión de bibliografía, y la redacción del manuscrito.

Financiación:

Este estudio fue financiado con recursos de la Estrategia de Sostenibilidad del Comité para el Desarrollo de la Investigación (CODI) de la Universidad de Antioquia y los recursos administrativos del Fondo de Apoyo Docente de la Facultad Nacional de Salud Pública.

Conflicto de intereses:

No existe ninguno.
Prevalence of opportunistic infections in insured patients with HIV and their association with socioeconomic and clinical factors in Colombia, 2012

Introduction: Despite advances in treatment, opportunistic infections are the major cause of morbidity and mortality among patients with the human immunodeficiency virus (HIV). Objectives: To estimate the prevalence of opportunistic infections among insured HIV patients, and to establish its association with socio-demographic and clinical factors. Materials and methods: This was an observational study with an analytical focus. We analysed 37,325 records of insured people with HIV. A bivariate analysis using chi square and ANOVA, adjusted by Bonferroni, and multiple logistic regression for the adult population were carried out to explore the association among any opportunistic infections as the response variable and socio-demographic and clinical factors.

Results: From the total, at least $18 \%$ experienced an opportunistic infection. The most frequent were tuberculosis and brain toxoplasmosis for adults, and pneumonia and diarrhea for patients under 13 years of age. The prevalence of any opportunistic infection was significantly higher in men $\left(\mathrm{OR}=1.5 ; \mathrm{Cl}_{95 \%} 1.4-1.6\right)$, in those more than 40 years of age $\left(\mathrm{OR}=1.6 ; \mathrm{Cl}_{95 \%} 1.3-2.0\right)$, in people subjected to forced displacement $\left(\mathrm{OR}=1.7 ; \mathrm{Cl}_{95 \%} 1.5-\right.$ 1.9 ), and in those belonging to the subsidized or exception health affiliation regimes (OR=2.7; $\mathrm{Cl}_{95 \%}$ 2.1-3.4). Regarding clinical factors, opportunistic infections were significantly associated to time since diagnosis ( $>10$ years) $\left(\mathrm{OR}=1.6 ; \mathrm{Cl}_{95 \%} 1.5-1.7\right)$, administration of antiretroviral treatment $\left(\mathrm{OR}=4.4 ; \mathrm{Cl}_{95 \%} 3.9-5.1\right)$, and discontinuity of treatment $\left(\mathrm{OR}=1.7 ; \mathrm{Cl}_{95 \%} 1.6-1.8\right)$. The multivariate analysis for adults in clinical stage A showed similar results.

Conclusions: Despite the preventable nature of opportunistic infections, their prevalence is high and they predominantly affect the most disadvantaged people.

Key words: Opportunistic infections/epidemiology; HIV infections; socioeconomic factors; health status disparities; health systems. 
Las infecciones oportunistas son aquellas que ocurren cuando el sistema inmunitario está deprimido. Son la principal causa de morbilidad, discapacidad y mortalidad en pacientes con el virus de la inmunodeficiencia humana (HIV) y, además, son responsables de un gran número de hospitalizaciones y de altos costos en la atención (1-3). A pesar del progreso en el tratamiento antirretroviral y en la profilaxis, las infecciones oportunistas continúan siendo un problema de salud pública en Colombia y en otros países, principalmente aquellos de ingresos bajos (4-10). Estas infecciones producen una serie de complicaciones clínicas que disminuyen la calidad de vida de los pacientes e imponen una pesada carga a las familias y al sistema de salud (11).

Las personas con HIV pueden experimentar infecciones oportunistas producidas por hongos, virus, protozoos, bacterias o micobacterias. Su presencia en estos pacientes es el resultado de la depleción de los linfocitos T CD4 (12-14), especialmente cuando el cumplimiento del tratamiento antirretroviral es deficiente, ya que ello afecta negativamente la reacción virológica. La prevalencia de las infecciones oportunistas también se ha asociado con la detección tardía y el desconocimiento de los pacientes de su estado serológico, así como con la respuesta inapropiada del sistema de salud (11,15-20). Algunas de estas infecciones causan discapacidad, reducen la expectativa de vida y provocan la utilización intensiva de los servicios de salud, especialmente de hospitalización y cuidados intensivos (21).

A diferencia de lo que sucede en países con altos ingresos, en Colombia las hospitalizaciones para los pacientes con sida se debe principalmente a las infecciones oportunistas, especialmente la tuberculosis, la candidiasis esofágica y la encefalitis por toxoplasma (22).

En el país se han llevado a cabo algunos estudios aislados sobre la prevalencia de las infecciones oportunistas y se cuenta con datos muy generales sobre su prevalencia en personas con HIV. El Sistema de Vigilancia en Salud Pública (Sivigila) no reporta periódicamente el comportamiento de estas infecciones en pacientes con sida, y la única fuente de información disponible son los registros recolectados, auditados y publicados por el organismo técnico no gubernamental 'Cuenta de Alto Costo'. Cualquier esfuerzo de sistematizar esta información puede verse sesgado por dificultades estructurales del sistema de salud, como la fragmentación de los servicios, la segmentación de la atención de los pacientes y el deficiente proceso de vigilancia en salud pública. A pesar de estos problemas, se ha determinado que las enfermedades de mayor prevalencia en el país son, en su orden, la tuberculosis pulmonar, la neumonía por Pneumocystis spp., la toxoplasmosis y las infecciones por hongos (23).

Clínicamente, las infecciones oportunistas del pulmón son las más frecuentes, y les siguen el compromiso del sistema nervioso y de los ojos, y otras condiciones de carácter sistémico (24-31).

Algunos estudios aislados han permitido determinar la importancia clínica y social de estas enfermedades. Según datos de 1998, la prevalencia de la toxoplasmosis en Colombia estaba alrededor de 47,5 \% (32). En un estudio llevado a cabo en Cúcuta entre 1995 y 2005, se encontró que 171 pacientes tenían infecciones del sistema nervioso central, principalmente, encefalitis por Toxoplasma gondii $(56,5 \%)$, criptococosis meníngea $(38,9 \%)$ y tuberculosis meníngea (4,6 \%). De los pacientes afectados, solo el 31,3\% recibía tratamiento antirretroviral de alta efectividad (33). 
En el país hay muy pocas investigaciones sobre las infecciones oportunistas, y las existentes se han centrado en la tuberculosis y otras micobacterias. En Cali se hizo un estudio en el 2006 en el cual se registró una prevalencia de coinfección con HIV y micobacterias de 34,8 \%. El 6,6 \% de estos casos había sido ocasionado por Mycobacterium tuberculosis y el $27,7 \%$, por otras micobacterias (34).

En un estudio llevado a cabo en Medellín en el 2004, se encontró que de los 103 pacientes con HIV evaluados, el $70 \%$ tenía diarrea y el 3,9\% de estos presentaba microsporidiosis intestinal. También, se encontraron tres pacientes positivos para Enterocytozoon bieneusi y uno para Encephalitozoon intestinalis. La mayoría de los casos de microsporidiosis se asociaron con diarrea prolongada, con recuentos de linfocitos TCD4+ menores de 100 células/ $\mu$ y cargas virales superiores a 100.000 copias (35). Tanto los adultos como los niños fueron más sensibles a la criptosporidiosis, en la mayoría de los casos asociada con contaminación del agua (36).

Pese a estos estudios aislados y a los reportes generales de la prevalencia de las infecciones oportunistas en pacientes con HIV, hasta el momento no se ha realizado ningún estudio nacional que intente indagar por la prevalencia general y específica de tales infecciones en los diferentes subgrupos poblacionales, es decir, no se tiene información cierta sobre su asociación con las condiciones clínicas o sociodemográficas.

Por consiguiente, se desconocen las diferencias de las infecciones oportunistas según grupos de edad, condición de aseguramiento o condiciones de vulnerabilidad, cuya exploración es el objetivo principal del presente estudio. Se espera que los resultados permitan entender mejor la situación actual del país en este sentido y alertar a los prestadores de servicios, a las empresas administradores de planes de beneficios y a la autoridad sanitaria nacional sobre la importancia de intervenir este importante problema con un enfoque diferencial.

\section{Materiales y métodos}

\section{Diseño del estudio y objetivos}

Se hizo un estudio observacional con enfoque analítico a partir de información secundaria recolectada por la Cuenta de Alto Costo entre el 2011 y el 2012, con el fin de estimar la prevalencia de las infecciones oportunistas en los pacientes con HIV, y establecer su asociación con algunos factores clínicos y sociodemográficos.

\section{Fuente de información}

La base de datos utilizada es recopilada por la Cuenta de Alto Costo con base en el reporte bianual de todas las aseguradoras, conocidas en Colombia como empresas promotoras de salud (EPS), las cuales ejercen su papel de unidad notificadora y, a la vez, consolidan la información de las instituciones prestadoras de servicios de salud (IPS) adscritas a su red. Por norma, la Cuenta de Alto Costo ha sido delegada para consolidar la información referente al HIV y otras enfermedades de alto costo, y garantizar su calidad. El ministerio público ha delegado en esta institución la función de validar y auditar la información presentada, con el fin de hacer seguimiento y ajustar el riesgo financiero en el proceso del aseguramiento. La veracidad de la información emitida es certificada por los gerentes de cada EPS $(37,38)$. 
Esta base de datos contiene información de 107 variables sociodemográficas, clínicas y de atención. Incluye a todas las personas con HIV afiliadas al Sistema General de Seguridad Social en Salud (SGSSS), tanto en el régimen subsidiado como en el contributivo, pero excluye la información de las personas pobres no aseguradas y de aquellas con cobertura intermitente de aseguramiento.

\section{Población y muestra}

La población de estudio incluyó a las personas con HIV afiliadas al SGSSS durante el período de 2011 a 2012.

La base de datos primaria fue depurada según los objetivos del estudio; para garantizar la calidad de la información, se excluyeron los valores atípicos y aquellos casos con pérdida de más del $50 \%$ de los datos, por lo cual se analizaron 37.325 registros en total. Se encontró que, incluso después de la depuración, había registros sin información sobre algunas variables, lo cual exigió ajustar el número en cada análisis.

\section{Definición y operacionalización de las variables}

La variable de respuesta se determinó por la presencia, por lo menos, de una de las 15 infecciones oportunistas establecidas por los Centers for Disease Control and Prevention (CDC) en el 2008 (8). El diagnóstico y el registro de estas infecciones están a cargo de las respectivas unidades notificadoras. El análisis incluyó las seis variables sociodemográficas: edad, sexo, grupo étnico, grupo poblacional, tipo de afiliación al SGSSS y continuidad del aseguramiento. Además, incluyó siete variables clínicas: estadio clínico en el momento del diagnóstico de HIV según la clasificación para adultos y adolescentes y aquella para menores de 13 años $(39,40)$, el tiempo transcurrido desde el momento del diagnóstico de HIV, la carga viral al comienzo del tratamiento antirretroviral, el esquema de tratamiento antirretroviral, los cambios en el tratamiento, los tratamientos completos, es decir, recibidos doce meses seguidos, y algunas comorbilidades. La base de datos interna de la Cuenta de Alto Costo contiene los datos de identificación, lo que permite evitar los registros duplicados. Sin embargo, la base de datos pública utilizada en el presente estudio no contiene información que posibilite la identificación de los pacientes, con el fin de respetar la confidencialidad.

\section{Análisis estadístico}

Se hicieron análisis descriptivos y bivariados para calcular la prevalencia de las infecciones oportunistas y su asociación con las características sociodemográficas y clínicas; las diferencias significativas se establecieron con $p<0,05$, para un nivel de significación del $95 \%$.

La asociación entre las variables categóricas se estimó mediante las pruebas de ji al cuadrado y ANOVA, todas ajustadas con la corrección de Bonferroni para controlar el error de tipo 1 asociado con el gran tamaño de la muestra.

Por último, se utilizó un modelo de regresión logística múltiple tomando como variable de respuesta la presencia, por lo menos, de una de las infecciones oportunistas definidas según los criterios de los CDC. Las variables incluidas en el modelo se seleccionaron mediante el método de paso a paso y la normalidad de las variables se conformó mediante la prueba de Hosmer-Lemeshow, con un valor de $p$ menor de 0,25, y la bondad de ajuste. Posteriormente, se ordenaron las variables para la jerarquización según el valor del seudo-R al cuadrado y de Akaike. 
Con el fin de controlar factores de confusión como la edad y las infecciones oportunistas previas, se distribuyó el análisis en dos grupos: adultos $(n=36.669)$ con estadio $A$ y menores de 13 años $(n=656)$ con estadio $N$, ambos en el momento del diagnóstico inicial de HIV. En todos los casos se vigiló la presencia de colinealidad. El modelo para los niños presentó limitaciones en la distribución de las variables debidas al tamaño de la muestra y no se registró la significación.

A partir de estos modelos se calculó la razón de momios (odds ratio, OR) ajustada, con su respectivo intervalo de confianza de $95 \%\left(\mathrm{IC}_{95 \%}\right)$ para estimar la asociación entre las características sociodemográficas y clínicas con la presencia de, por lo menos, una infección oportunista. Los análisis se hicieron con el programa estadístico Stata ${ }^{\mathrm{TM}}$, versión 13.0.

\section{Consideraciones éticas}

El estudio se ajustó a los estándares y regulaciones vigentes en Colombia (41) y fue aprobado por el Comité de Ética de la Facultad Nacional de Salud Pública de la Universidad de Antioquia.

\section{Resultados}

En la Cuenta de Alto Costo se registraron 37.325 pacientes con HIV asegurados durante el período de estudio, de los cuales el $73,1 \%$ eran hombres. La media de edad fue de 40 años, con un rango entre 1 y 93 años. Con relación al origen étnico, solo el 2,0 \% pertenecía a minorías étnicas y el $3,9 \%$ pertenecía a grupos poblacionales vulnerables (desplazados o privados de la libertad). El 60,8\% estaba afiliado al régimen contributivo de salud.

Se reportaron 650 personas $(1,7 \%)$ con neoplasias y $2.301(6,2 \%)$ con síndrome de desgaste. El sarcoma de Kaposi tuvo una prevalencia de 1,3\%, el linfoma de Burkitt, de 0,2\% y el cáncer cervical en mujeres mayores de 15 años, de $0,7 \%$ (cuadro 1 ).

Cuadro 1. Características sociodemográficas de las personas con HIV afiliadas al Sistema General de Seguridad Social en Salud, 2012

\begin{tabular}{llcc}
\hline & & \multicolumn{2}{c}{ Total de la población con HIV } \\
\cline { 2 - 4 } & & $\mathrm{n}$ & $\%$ \\
\hline Sexo (n=37.325) & Femenino & 10.059 & 26,9 \\
& Masculino & 27.266 & 73,1 \\
& $<=13$ & 656 & 1,8 \\
& $14-29$ & 5.724 & 15,3 \\
& $30-39$ & 11.413 & 30,6 \\
Grupo poblacional (años) ( $\mathrm{n}=37.325)$ & $40-49$ & 11.224 & 30,1 \\
& $>=50$ & 8.308 & 22,3 \\
& Población general & 35.876 & 96,1 \\
Tipo de aseguramiento ( $\mathrm{n}=37.325)$ & 1.308 & 3,5 \\
& Desplazado & 141 & 0,4 \\
& Población privada de la libertad & 14.327 & 38,4 \\
& Régimen subsidiado & 22.691 & 60,8 \\
Grupo étnico $(\mathrm{n}=37.001)$ & Régimen de excepción & 307 & 0,8 \\
& Población general & 36.314 & 98,1 \\
& Minorías étnicas & 687 & 1,9 \\
& Afrodescendiente & 489 & 1,32 \\
& Indígena & 192 & 0,52 \\
& Gitano & 6 & 0,02 \\
\hline
\end{tabular}




\section{Prevalencia de infecciones oportunistas}

De las 37.325 personas con HIV, 6.662 (17,9\%) presentaban infecciones oportunistas y 9.248 las habían padecido previamente, en tanto que 2.054 ( $5,5 \%$ de aquellos con HIV) habían padecido más de una. De los 6.662 pacientes con infecciones oportunistas reportadas, el 69,2\% presentó un solo tipo de dichas infecciones, el $22,0 \%$, dos tipos y el $8,8 \%$, tres o más.

Las infecciones oportunistas más prevalentes fueron, en su orden, la tuberculosis, la candidiasis y la toxoplasmosis cerebral, cada una con una prevalencia mayor de 3,6\%.

La prevalencia de infecciones oportunistas en hombres fue de 19,4 $\%\left(\mathrm{IC}_{95 \%} 18,9-19,9\right)$ y en las mujeres fue de $13,6 \%\left(\mathrm{IC}_{95 \%} 13,6-14,3\right)$. Se observó una prevalencia mayor en los hombres, con una diferencia estadísticamente significativa.

Dado que era inferior a 0,7\%, se agregó la prevalencia de otras infecciones oportunistas, como la histoplasmosis, la leucoencefalopatía multifocal progresiva, la coccidiodomicosis extrapulmonar, la neumonía linfoide intersticial y la septicemia por Salmonella spp y por especies de micobacterias (cuadro 2).

\section{Prevalencia de infecciones oportunistas según grupos de edad}

La prevalencia de las infecciones oportunistas siguió un patrón ascendente a medida que se incrementaba la edad. Entre los niños menores de 13 años, su prevalencia fue de 13,7\% (90/656). Las más frecuentes en este grupo de edad fueron la neumonía bacteriana, con una prevalencia de 5,0\%, la tuberculosis $(4,1 \%)$ y la neumonía por Pneumocystis jirovecii $(3,2 \%)$. En el resto de los grupos de edad, las infecciones más prevalentes fueron la tuberculosis (rango: $3,6-6,9 \%$ ), la candidiasis (rango: $2,0-5,5 \%$ ) y la toxoplasmosis cerebral (rango: $1,5-4,8 \%$ ), con leves variaciones entre los grupos. Las diarreas ocuparon el tercer lugar en la población entre 14 y 29 años de edad, con una prevalencia de 1,7\%. En la población mayor de 40 años, la prevalencia de infecciones oportunistas fue superior al $20 \%$ (cuadro 3, figura 1).

Cuadro 2. Prevalencia de infecciones oportunistas por sexo en pacientes con HIV afiliados al Sistema General de Seguridad Social en Salud, 2012

\begin{tabular}{|c|c|c|c|c|c|c|c|}
\hline & \multicolumn{7}{|c|}{ Prevalencia de infecciones oportunistas } \\
\hline & \multicolumn{2}{|r|}{ Total } & \multicolumn{2}{|c|}{ Femenino } & \multicolumn{2}{|c|}{ Masculino } & \multirow{2}{*}{$\frac{\mathbf{p}}{\mathrm{Ji}^{2}}$} \\
\hline & $\mathrm{n}$ & $\%\left(\mathrm{IC}_{95 \%}\right)$ & $\mathrm{n}$ & $\%\left(I_{95 \%}\right)$ & $\mathrm{n}$ & $\%\left(I_{95 \%}\right)$ & \\
\hline Personas con infecciones oportunistas & 6.662 & $17,9(17,5-18,2)$ & 1.369 & $13,6(12.9-14.3)$ & 5293 & $19,4(18,9-19,9)$ & $<0,01$ \\
\hline Mycobacterium tuberculosis & 2.123 & $5,68(5,45-5,92)$ & 416 & $4,13(3,75-4,54)$ & 1707 & $6,26(5,97-6,55)$ & 0,02 \\
\hline Diarrea & 914 & $2,44(2,29-2,61)$ & 198 & $1,96(1,70-2,25)$ & 716 & $2,62(2,43-2,82)$ & 0,01 \\
\hline Neumonía por Pneumocystis jirovecii & 907 & $2,43(2,27-2,59)$ & 178 & $1,76(1,52-2,04)$ & 729 & $2,67(2,48-2,87)$ & 0,01 \\
\hline Herpes simplex & 696 & $1,86(1,72-2,00)$ & 136 & $1,35(1,13-1,59)$ & 560 & $2,05(1,88-2,22)$ & 0,01 \\
\hline Criptococosis & 471 & $1,26(1,15-1,38)$ & 66 & $0,65(0,50-0,83)$ & 405 & $1,48(1,34-1,63)$ & 0,01 \\
\hline Neumonía bacteriana & 469 & $1,25(1,14-1,37)$ & 115 & $1,14(0,94-1,37)$ & 354 & $1,29(1,16-1,43)$ & $<0,01$ \\
\hline Citomegalovirus & 344 & $0,92(0,82-1,02)$ & 52 & $0,51(0,38-0,67)$ & 292 & $1,07(0,95-1,20)$ & $<0,01$ \\
\hline
\end{tabular}

Nota: prevalencia calculada sobre el denominador correspondiente a cada sexo; valor de $p$ ajustado mediante el método de Bonferroni 
Cuadro 3. Prevalencia de las infecciones oportunistas por grupos de edad en pacientes con HIV afiliados al Sistema General de Seguro Social en Salud, 2012

\begin{tabular}{|c|c|c|c|c|c|c|c|c|c|c|c|}
\hline & \multicolumn{11}{|c|}{ Grupos de edad (años) } \\
\hline & \multicolumn{2}{|r|}{$<=13$} & \multicolumn{2}{|r|}{$14-29$} & \multicolumn{2}{|r|}{$30-39 \mathrm{~s}$} & \multicolumn{2}{|r|}{$40-49$} & \multicolumn{2}{|r|}{$>=50$} & \multirow{2}{*}{$\frac{\mathbf{p}}{\mathrm{ji}^{2}}$} \\
\hline & $\mathrm{n}$ & $\%$ & $\mathrm{n}$ & $\%$ & $\mathrm{n}$ & $\%$ & $\mathrm{n}$ & $\%$ & $\mathrm{n}$ & $\%$ & \\
\hline Pacientes con HIV & 656 & & 5724 & & 11413 & & 11224 & & 8308 & & \\
\hline $\begin{array}{l}\text { Presencia de } \\
\text { infecciones } \\
\text { oportunistas }\end{array}$ & 90 & $13,7(11,2-16,6)$ & 617 & $10,8(10,0-11,6)$ & 1842 & $16,1(15,5-16,8)$ & 2285 & $20,4(19,6-21,1)$ & 1828 & $22,0(21,1-22,9)$ & $<0,01$ \\
\hline $\begin{array}{l}\text { Mycobacterium } \\
\text { tuberculosis }\end{array}$ & 27 & $4,1(2,7-5,9)$ & 208 & $3,6(3,1-4,1)$ & 621 & $5,4(5,0-5,8)$ & 694 & $6,2(5,7-6,6)$ & 573 & $6,9(6,3-7,4)$ & $<0,01$ \\
\hline Candidiasis & 12 & $1,8(0,9-3,2)$ & 115 & $2,0(1,6-2,4)$ & 357 & $3,1(2,8-3,4)$ & 449 & $4,0(3,6-4,3)$ & 458 & $5,5(5,0-6,0)$ & $<0,01$ \\
\hline $\begin{array}{l}\text { Toxoplasmosis } \\
\text { cerebral }\end{array}$ & 6 & $0,9(0,3-2,0)$ & 87 & $1,5(1,2-1,8)$ & 405 & $3,5(3,2-3,9)$ & 542 & $4,8(4,4-5,2)$ & 320 & $3,9(3,4-4,2)$ & $<0,01$ \\
\hline Diarreas & 19 & $2,9(1,8-4,5)$ & 102 & $1,7(1,4-2,1)$ & 258 & $2,3(1,9-2,5)$ & 299 & $2,7(2,3-2,9)$ & 236 & $2,8(2,4-3,2)$ & $<0,01$ \\
\hline $\begin{array}{l}\text { Neumonía por } \\
\text { Pneumocystis } \\
\text { jirovecii }\end{array}$ & 21 & $3,2(2,0-4,9)$ & 76 & $1,3(1,0-1,6)$ & 249 & $2,2(1,9-2,4)$ & 314 & $2,8(2,5-3,1)$ & 247 & $3,0(2,6-3,3)$ & $<0,01$ \\
\hline Herpes simplex & 5 & $0,8(0,3-1,8)$ & 74 & $1,2(1,0-1,6)$ & 177 & $1,6(1,3-1,7)$ & 236 & $2,1(1,8-2,3)$ & 204 & $2,5(2,1-2,8)$ & $<0,01$ \\
\hline Criptococosis & 2 & $0,3(0,04-1,1)$ & 35 & $0,6(0,4-0,8)$ & 131 & $1,1(0,9-1,3)$ & 187 & $1,7(1,4-1,9)$ & 116 & $1,4(1,1-1,6)$ & $<0,01$ \\
\hline $\begin{array}{l}\text { Neumonía } \\
\text { bacteriana }\end{array}$ & 33 & $5,0(3,5-7,0)$ & 54 & $0,9(0,7-1,2)$ & 125 & $1,1(0,9-1,3)$ & 136 & $1,2(1,0-1,4)$ & 121 & $1,5(1,2-1,7)$ & $<0,01$ \\
\hline Citomegalovirus & 2 & $0,3(0,04-1,1)$ & 26 & $0,4(0,2-0,6)$ & 90 & $0,8(0,6-0,9)$ & 127 & $1,1(0,9-1,3)$ & 99 & $1,2(0,9-1,4)$ & $<0,01$ \\
\hline $\begin{array}{l}\text { Otras infecciones } \\
\text { oportunistas }\end{array}$ & 8 & $1,2(0,5-2,4)$ & 68 & $0,4(0,9-1,5)$ & 172 & $0,8(1,2-1,7)$ & 191 & $1,1(1,4-1,9)$ & 134 & $1,2(1,3-1,9)$ & $<0,01$ \\
\hline
\end{tabular}

\section{Infecciones oportunistas y su asociación con las características sociodemográficas}

Las personas desplazadas presentaron prevalencias de $26,4 \%$, con un riesgo $69 \%$ mayor comparado con el de la población general. Asimismo, la población indígena presentó prevalencias de $23,9 \%$, con un riesgo $46 \%$ superior al exhibido por la población general.

Con relación al régimen de afiliación al SGSSS, se observó menor prevalencia de infecciones oportunistas entre los afiliados al régimen contributivo. Los afiliados a los regímenes de excepción presentaron 2,7 veces más riesgo de presentar dichas infecciones que los afiliados al régimen subsidiado, diferencias que fueron estadísticamente significativas. Asimismo, aquellos con discontinuidad en el aseguramiento tuvieron $48 \%$ más riesgo de desarrollar infecciones oportunistas que quienes permanecieron en el mismo régimen desde el momento del diagnóstico $\left(\mathrm{OR}=1,48 ; \mathrm{IC}_{95 \%} 1,41-1,57\right)$ (cuadro 4).

\section{Infecciones oportunistas y su asociación con las características clínicas}

La frecuencia de las infecciones oportunistas fue significativamente mayor entre aquellos diagnosticados con HIV diez o más años atrás, así como entre quienes registraban valores de carga viral al inicio del tratamiento antirretroviral.

El $88 \%$ de las personas recibía tratamiento antirretroviral y el 19,6\% (6.425/32.780) de ellos presentaron infecciones oportunistas. Las personas que recibían el tratamiento registraban dichas infecciones con mayor frecuencia, con una OR de 4,4 $\left(\mathrm{IC}_{95 \%} 3,9-5,1\right)$. 


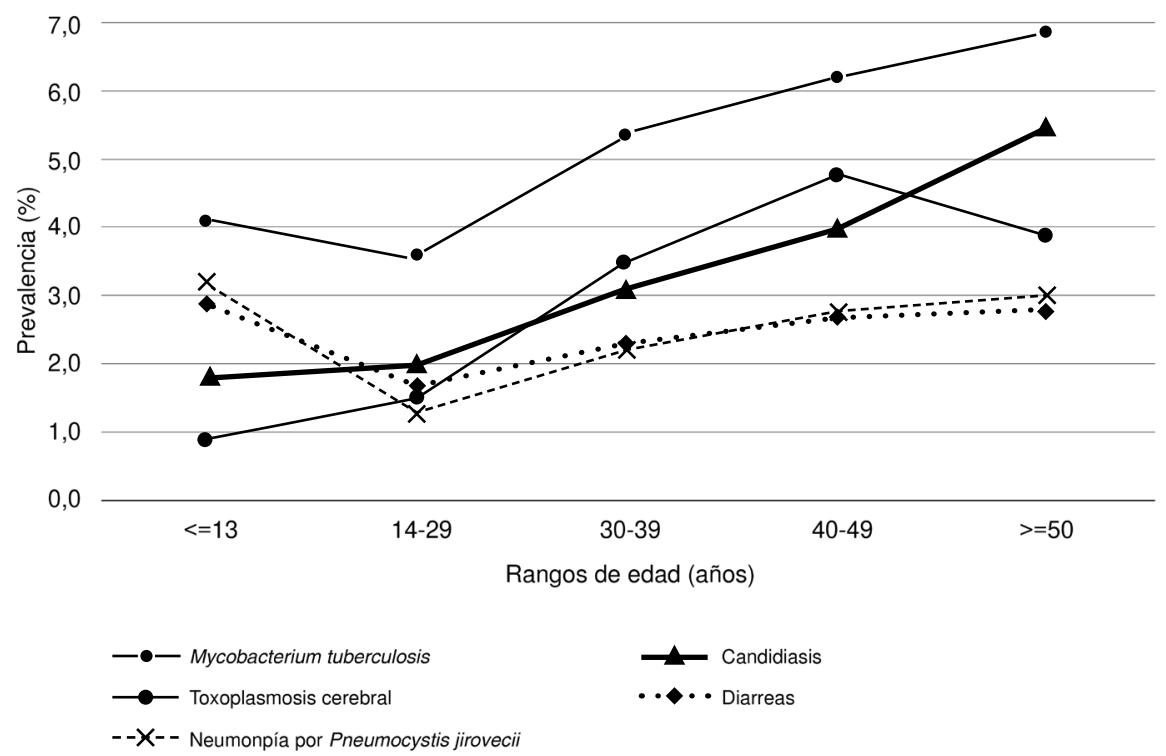

Figura 1. Prevalencia de las principales infecciones oportunistas en pacientes con HIV afiliados al Sistema General de Seguridad Social en Salud, 2012

De los pacientes con infecciones oportunistas que recibían tratamiento antirretroviral, el 16,7 \% (3.056) lo había recibido completo durante los 12 meses del año, en tanto que los pacientes que no completaban el tratamiento tenían un $65 \%$ de riesgo adicional de presentar infecciones oportunistas en comparación con quienes recibieron el tratamiento completo. El $61,8 \%$ de los pacientes cambió el esquema de tratamiento por decisión clínica y, de estos, el 15,8\% presentó infecciones oportunistas. El $38,2 \%$ de los pacientes aceptó voluntariamente cambios en el esquema terapéutico y, de estos, el $25,4 \%$ presentó infecciones oportunistas. Las personas que cambiaron el esquema de manera voluntaria presentaron un $81 \%$ de riesgo adicional en comparación con quienes lo hicieron por decisión clínica (cuadro 4).

Según el modelo multivariado, los factores asociados con la presencia de infecciones oportunistas en los pacientes adultos con enfermedad en estadio A en el momento del diagnóstico de HIV, fueron el sexo masculino $(\mathrm{OR}=1,51$; $\left.\mathrm{IC}_{95 \%} 1,3-1,7\right)$, el régimen de seguridad social al cual estaban afiliados, siendo mayor el riesgo para la población en regímenes de excepción $(\mathrm{OR}=6,1$; $\left.\mathrm{IC}_{95 \%} 4,4-8,4\right)$, el desplazamiento (OR=1,4; $\left.\mathrm{IC}_{95 \%} 1,1-1,8\right)$, y un tiempo mayor de diez años desde el momento del diagnóstico (OR=1,2; $\left.I C_{95 \%} 1,0-1,4\right)$. También, se observó un aumento del riesgo a medida que aumentaba la edad, así como en los pacientes que recibieron el tratamiento antirretroviral $\left(\mathrm{OR}=2,0 ; \mathrm{IC}_{95 \%}, 1,4-2,8\right)$ y en aquellos que cambiaron el esquema de medicación por voluntad propia (OR=2,0; $\left.\mathrm{IC}_{95 \%}, 1,8-2,2\right)$ (cuadro 5).

\section{Discusión}

En el estudio se analizaron 37.325 registros de pacientes incluidos en la base de datos nacional de la Cuenta de Alto Costo durante el 2011 y el 2012. Durante ese mismo período las fuentes oficiales reportaron 65.638 personas con HIV (42). El hecho de que cerca de $57 \%$ de la población se excluyó del 
Cuadro 4. Prevalencia de cualquier infección oportunista y su asociación con las características sociodemográficas y clínicas de pacientes con HIV afiliados al Sistema General de Seguridad Social en Salud, 2012

\begin{tabular}{|c|c|c|c|c|c|c|}
\hline & $\mathbf{n}$ & $\begin{array}{c}\text { Con } \\
\text { infecciones } \\
\text { oportunistas }\end{array}$ & $\%$ & $\begin{array}{c}\text { Sin } \\
\text { infecciones } \\
\text { oportunistas }\end{array}$ & $\%$ & ${ }^{*}$ OR (IC ${ }^{95 \%)}$ \\
\hline Total & 37.325 & 6.662 & 17,8 & 30.663 & 82,2 & \\
\hline Sexo & 37.325 & & & & & \\
\hline Femenino & 10.059 & 1.369 & 13,6 & 8.690 & 86,4 & Grupo de referencia \\
\hline Masculino & 27.266 & 5.293 & 19,4 & 21.973 & 80,6 & \\
\hline Edad (años) & 37.325 & & & & & \\
\hline$\leq 13$ & 656 & 90 & 13,7 & 566 & 86,3 & Grupo de referencia \\
\hline $14-29$ & 5.724 & 617 & 10,7 & 5.107 & 89,2 & $0,76(0,60-0,96)$ \\
\hline $30-39$ & 11.413 & 1.842 & 16,1 & 9.571 & 83,9 & $1,21(0,96-1,52)$ \\
\hline $40-49$ & 11.224 & 2.285 & 20,3 & 8.939 & 79,6 & $1,61(1,28-2,02)$ \\
\hline$\geq 50$ & 8.308 & 1.828 & 22,0 & 6.480 & 78,0 & $1,77(1,41-2,23)$ \\
\hline Grupo poblacional & 37.325 & & & & & \\
\hline Población general & 35.876 & 6.300 & 17,5 & 29.576 & 82,4 & Grupo de referencia \\
\hline Desplazado & 1.308 & 346 & 26,4 & 962 & 73,5 & $1,69(1,49-1,91)$ \\
\hline Población privada de la libertad & 141 & 16 & 11,3 & 125 & 88,7 & $0,60(0,36-1,01)$ \\
\hline Grupo étnico & 37.001 & & & & & \\
\hline Población general & 36.314 & 6.541 & 18,0 & 29.773 & 82,0 & Grupo de referencia \\
\hline Afro descendiente & 489 & 74 & 15,1 & 415 & 84,9 & $0,82(0,64-1,06)$ \\
\hline Indígena & 192 & 46 & 23,9 & 146 & 76,0 & $1,46(1,05-2,03)$ \\
\hline Gitano & 6 & 1 & 16,6 & 5 & 83,3 & $0,92(0,11-7,92)$ \\
\hline Tipo de aseguramiento & 37.325 & & & & & \\
\hline Régimen subsidiado & 14.327 & 2.631 & 18,3 & 11.696 & 81,6 & Grupo de referencia \\
\hline Régimen contributivo & 22.691 & 3.915 & 17,2 & 18.776 & 82,7 & $0,93(0,88-0,98)$ \\
\hline Régimen de excepción & 307 & 116 & 37,7 & 191 & 62,2 & $2,70(2,14-3,41)$ \\
\hline Discontinuidad en aseguramiento & 37.325 & & & & & \\
\hline Continuidad & 24.880 & 3.944 & 15,8 & 20.936 & 84,1 & Grupo de referencia \\
\hline Discontinuidad & 12.445 & 2.718 & 21,8 & 9727 & 78,2 & $1,48(1,41-1,57)$ \\
\hline Tiempo desde el diagnóstico (años) & 37.325 & & & & & \\
\hline Menos de 10 años & 31.870 & 5.347 & 16,7 & 26.523 & 83,2 & Grupo de referencia \\
\hline Más de 10 años & 5.455 & 1.315 & 24,1 & 4140 & 75,9 & $1,58(1,47-1,69)$ \\
\hline Carga viral (al comienzo del TAR) (copias) & 19.496 & & & & & \\
\hline Indetectable & 1.163 & 155 & 13,3 & 1.008 & 86,7 & Grupo de referencia \\
\hline$<1.000$ copias & 2.830 & 542 & 19,1 & 2.288 & 80,8 & $1,54(1,27-1,87)$ \\
\hline 1.000 o más & 15.503 & 2.951 & 19,0 & 12.552 & 81,0 & $1,53(1,29-1,82)$ \\
\hline Personas que recibían tratamiento antirretroviral & 37.325 & & & & & \\
\hline No & 4.545 & 237 & 5,2 & 4.308 & 94,8 & Grupo de referencia \\
\hline Sí & 32.780 & 6.425 & 19,6 & 26.355 & 80,4 & $4,4(3,9-5,1)$ \\
\hline Continuidad de la tratamiento antirretroviral & 25.726 & & & & & \\
\hline $\mathrm{Si}^{\star}(12$ meses $)$ & 18.243 & 3.056 & 16,7 & 15.187 & 83,2 & Grupo de referencia \\
\hline No (0 a 11 meses) & 7.483 & 1.868 & 24,9 & 5.615 & 75,0 & $1,65(1,55-1,76)$ \\
\hline Cambio de tratamiento antirretroviral & 33.094 & & & & & \\
\hline Decisión clínica & 20.443 & 3.242 & 15,8 & 17.201 & 84,1 & Grupo de referencia \\
\hline Voluntario/renuncia & 12.651 & 3.219 & 25,4 & 9.432 & 74,6 & $1,81(1,71-1,91)$ \\
\hline
\end{tabular}

análisis sugiere que más de un tercio de los pacientes con HIV correspondía a la categoría de pobre no asegurado o a pacientes sin acceso al sistema de salud, por lo cual podría haber subestimación de las prevalencias aquí presentadas, especialmente en los grupos socialmente marginados.

Los datos disponibles mostraron que el $17,8 \%$ de la población estudiada sufría, por lo menos, de una de las infecciones oportunistas analizadas, siendo común la presencia de dos o más de ellas. La prevalencia fue significativamente mayor en hombres, en mayores de 40 años, en población desplazada, en población indígena, en personas afiliadas al régimen subsidiado o de excepción, así como en aquellos que tuvieron discontinuidad en el aseguramiento $o$ en el tratamiento antirretroviral. 
Cuadro 5. Factores asociados a la presencia de cualquier infección oportunista en adultos con HIV en estadio A según el modelo de regresión logística múltiple

\begin{tabular}{|c|c|c|c|c|}
\hline & OR & EE & $\mathbf{p}\left(j \mathbf{i}^{2}\right)$ & $\mathrm{IC}^{95 \%}$ \\
\hline Sexo masculino & 1,5 & 0,1 & $<0,001$ & $1,3-1,7$ \\
\hline \multicolumn{5}{|l|}{ Régimen } \\
\hline Contributivo & \multicolumn{4}{|c|}{ Grupo de referencia } \\
\hline Subsidiado & 2,0 & 0,1 & $<0,001$ & $1,8-2,2$ \\
\hline Excepción & 6,1 & 0,9 & $<0,001$ & $4,4-8,4$ \\
\hline \multicolumn{5}{|l|}{ Grupo poblacional } \\
\hline Población general & \multicolumn{4}{|c|}{ Grupo de referencia } \\
\hline Desplazado & 1,38 & 0,2 & 0,02 & $1,1-1,8$ \\
\hline Población privada de la libertad & 1,1 & 0,5 & 0,9 & $0,4-2,6$ \\
\hline Tiempo desde el diagnóstico (más de 10 años) & 1,2 & 0,1 & 0,01 & $1,0-1,4$ \\
\hline \multicolumn{5}{|l|}{ Rango de edad (años) } \\
\hline $14-29$ & \multicolumn{4}{|c|}{ Grupo de referencia } \\
\hline $30-39$ & 1,3 & 0,1 & 0,07 & $1,1-1,6$ \\
\hline $40-49$ & 1,4 & 0,1 & $<0,001$ & $1,2-1,7$ \\
\hline$\geq 50$ & 1,63 & 0,2 & $<0,001$ & $1,3-2,0$ \\
\hline Reciben tratamiento antirretroviral & 2,0 & 0,1 & $<0,001$ & $1,4-2,8$ \\
\hline Cambio de medicación (voluntario/renuncia) & 2,0 & 0,1 & $<0,001$ & $1,80-2,24$ \\
\hline
\end{tabular}

OR: odds ratio; EE: error estándar

En cuanto a las comparaciones con otros estudios, deben hacerse tres precisiones:

1) las infecciones oportunistas aquí reportadas corresponden al listado de los CDC, el cual subestima la frecuencia y la magnitud de otros microorganismos oportunistas emergentes de importancia clínica que afectan a los pacientes con HIV, como el virus BK, Candida auris $(43,44)$ y especies de Cryptococcus no neoformans, entre otros (45);

2) la prevalencia de las infecciones oportunistas puede cambiar según la calidad del sistema de salud y de la atención, del registro y de la notificación.

El diagnóstico y el registro de estas infecciones están a cargo de cada una de las unidades notificadoras, y su diagnóstico se basa en protocolos clínicos y administrativos que pueden variar entre las IPS, así como en el uso de técnicas microbiológicas que ofrecen diferentes grados de sensibilidad y especificidad.

El proceso de detección y registro de tales infecciones para el diagnóstico apropiado, oportuno y diferencial, no siempre se logra de manera precisa debido a las carencias o limitaciones en los conocimientos, los recursos y las tecnologías médicas, y

3) desde un punto de vista más general, es factible que las deficiencias en el sistema relacionadas con la búsqueda y utilización de servicios de salud, u otros fenómenos de naturaleza geográfica, así como con la exclusión social y sanitaria a la que se ven expuestos algunos grupos poblacionales, puedan explicar parcialmente las diferencias en la prevalencia (46-48). Además, las diferencias en la calidad de la atención y el reporte podrían introducir un sesgo de información que lleve a subestimarla.

La comparación de la prevalencia de las infecciones oportunistas entre países, puede ser una tarea compleja, pues la vigilancia, el reporte y el diseño de investigación varían y, además, los grupos de población estudiados pueden tener condiciones clínicas, sociales y ambientales que no son comparables. Sin embargo, las cifras a nivel internacional que se señalan a continuación, pueden ser útiles como referencia. 
Aunque las tasas de sida e infecciones oportunistas en países de ingresos altos han disminuido sin tregua en los años recientes, aún se consideran inaceptablemente altas dado su carácter prevenible. En una revisión sistemática, se encontró que la incidencia de tales infecciones en los países de ingresos altos variaba entre 5,5 y 50 por 100 personas al año, y la prevalencia entre 27,4 y $56,7 \%$, en tanto que en los países de ingresos bajos y medios la incidencia fue de 12,2 a 93,9 por año y la prevalencia estuvo entre 32,0 y 77,7 \% (46).

En Alemania, por ejemplo, la incidencia reportada en el 2013 fue de 28,4 \% (49). En los Estados Unidos, se ha registrado una notable reducción en la incidencia de estas infecciones, aunque continúan estando entre las principales causas de morbilidad y mortalidad (18,50). En un estudio en Brasil, entre 1987 y 2002 , se reportaron frecuencias de infecciones oportunistas cercanas al $33 \%$ en cohortes específicas, con una incidencia de 4,6 por 100 pacientes asintomáticos por año (10). En Nigeria la prevalencia de estas infecciones en el 2017 ascendió a 46,6 \% en un grupo de pacientes mayores de 50 años (51), y los resultados que se presentan aquí evidenciaron prevalencias superiores al $20 \%$ en este rango de edad. En un estudio de un hospital de India en el 2017, se registró una prevalencia que osciló entre 55,6 y 66,7 \%, y fue mayor en pacientes con conteos de CD4 inferiores a 200 células/ $\mu$ (52).

En el presente estudio, se evidenció que las neumonías y la diarrea eran las infecciones oportunistas más frecuentes en niños, en tanto que la tuberculosis, la candidiasis y la toxoplasmosis cerebral fueron las más prevalentes en adultos, con valores superiores a 3,6\%. Estas últimas también se han reportado como las más prevalentes en Brasil y Uganda (5355), en tanto que en un estudio en Japón se encontró que la tuberculosis y la neumonía por Pneumocystis fueron las más frecuentes (56).

En este estudio se encontró una prevalencia de tuberculosis de 5,7\% y en estudios a nivel internacional se ha señalado que los pacientes con HIV tienen un riesgo hasta 37 veces mayor de desarrollar esta enfermedad que quienes no tienen HIV. En este grupo de pacientes la tuberculosis es una de las mayores causas de muerte en el mundo (57).

En el presente estudio, se registró una prevalencia de toxoplasmosis cerebral - enfermedad que se considera fatal- de 3,6 \%, cifra baja comparada con otros lugares como Estados Unidos, donde uno de cada tres pacientes con sida la adquiere, o países de Europa y África, donde afecta hasta a la mitad de estos pacientes (58).

Vale la pena mencionar que dado que clínicamente la neumonía por $P$. jirovecii es similar a la toxoplasmosis pulmonar, el diagnóstico diferencial no es suficientemente claro y la prevalencia de estas enfermedades podría estar subestimada (59).

En este estudio se encontró que la prevalencia de diarrea fue de 2,4 \%, cifra ligeramente inferior a la reportada por Wang, et al., quienes señalaron que la alta prevalencia de la diarrea estaba relacionada con coccidias de los géneros Cryptosporidium e Isospora y con microsporidios, cuya frecuencia promedio se estimó en 14, 2,5 y $11 \%$, respectivamente, y fue mayor en los países de ingresos bajos (60).

En el presente estudio, se encontró una prevalencia de criptococosis de $1,3 \%$, cifra por debajo de la estimada en Irán (3\%) y muy inferior a la reportada en otros países de América Latina, en China y en Botsuana, donde 
representa una gran carga de enfermedad $(61,62)$. La baja prevalencia de las infecciones oportunistas en Colombia registrada en el presente estudio, comparada con las cifras internacionales, podría sugerir deficiencias importantes en el diagnóstico, además de subregistro, hipótesis que deberá ser comprobada en futuros estudios.

Hubo diferencias estadísticamente significativas en la prevalencia de las infecciones oportunistas en aquellos que no habían tenido continuidad en el aseguramiento o en el tratamiento. Como ya se mencionó, la base de datos utilizada incluía únicamente personas aseguradas, pero incluso entre ellas, el 66,7 \% registró discontinuidad en la afiliación al sistema y el 70,9 $\%$, en el tratamiento. Ambas variables constituyeron factores de riesgo para desarrollar infecciones oportunistas. La prevalencia de estas infecciones fue significativamente mayor en pacientes de los regímenes subsidiado y de excepción. Hasta donde se sabe, son pocos los estudios adelantados en el país para establecer la asociación entre dichas infecciones y las inequidades sociales, y tampoco abundan aquellos en los que la continuidad en el aseguramiento se haya empleado como indicador para identificar desigualdades en salud. Este indicador resulta interesante para utilizarlo en futuros estudios.

En cuanto a las características clínicas, se encontró que solo el 19,6 \% de las personas con infecciones oportunistas había recibido tratamiento antirretroviral y que quienes lo recibieron tuvieron un riesgo mayor de contraerlas que aquellos que no lo recibieron. Por falta de datos en las series de tiempo, no fue posible calcular el efecto causado por la introducción del tratamiento antirretroviral en la prevalencia de dichas infecciones. En un estudio en Brasil, entre 2009 y 2012, se reportó una incidencia menor de 3,4 por 100 por año, atribuible a la disponer de mejores tratamientos (53).

Según los registros analizados en este estudio, el $87,8 \%$ de las personas con HIV recibieron tratamiento antirretroviral en el país y el acceso al tratamiento varió entre 31,3 y $91 \%$ según diversos reportes $(15,33,63)$. Al igual que en otros estudios $(47,48)$, también en este se encontró que en $30 \%$ de los pacientes hubo discontinuidad en el tratamiento.

El desarrollo de infecciones oportunistas en 19,6\% de los pacientes bajo tratamiento antirretroviral podría explicarse por fallas en el esquema terapéutico ofrecido, falta de un esquema profiláctico adecuado, o problemas de cumplimiento del tratamiento, resistencia viral o falta de educación relacionada con el autocuidado. Estas hipótesis, sin embargo, tendrán que ser verificadas mediante nuevos estudios.

Algunos autores han sugerido que la gran frecuencia de las infecciones oportunistas estaría asociada con las limitaciones para garantizar un diagnóstico y tratamiento adecuados y oportunos $(64,65)$, así como una adecuada retención y cumplimiento. En este sentido, en un estudio en Colombia, se encontró que el $28 \%$ de la población hospitalizada desconocía su diagnóstico, solo el $60 \%$ estaba en programas de seguimiento y recibía tratamiento antirretroviral y menos del $55 \%$ cumplía con este (22). En el país no se cuenta con registros oficiales que permitan conocer la utilización y el cumplimiento de los tratamientos.

Es importante anotar que la administración adecuada y oportuna del tratamiento antirretroviral puede prevenir millones de muertes y complicaciones (66-68). Además de la oportunidad del tratamiento, los pacientes con alteración del sistema inmunitario deberían recibir profilaxis 
para prevenir que las infecciones latentes evolucionen a infecciones activas con manifestaciones clínicas (profilaxis primaria) o para prevenir la recurrencia (profilaxis secundaria) $(7,8)$.

La profilaxis en pacientes con HIV es tan importante que en algunos estudios se ha reportado que el número de CD4+ aumenta en quienes la reciben y, por lo tanto, se reduce la aparición de infecciones oportunistas (69-71). Por el contrario, el riesgo de mortalidad entre quienes no la reciben es 10 veces mayor (9). Para que el tratamiento farmacológico sea eficaz debe ser suministrado por personal altamente calificado, con el fin de evitar las interacciones medicamentosas y los efectos tóxicos que amenazan la vida de los pacientes (72). Hasta el momento, no se conocen estudios en Colombia que permitan establecer la utilización de la profilaxis para el control de las infecciones oportunistas.

Las infecciones oportunistas aumentan la discapacidad, la morbilidad y la mortalidad $(42,66,73-76)$. Las infecciones oportunistas se han asociado con trastornos neurocognitivos, con el síndrome inflamatorio de reconstitución inmunitaria, y con limitaciones auditivas, orales y visuales (52,73,77-80). Dada la ausencia de datos sobre la discapacidad y la mortalidad causadas por las infecciones oportunistas en Colombia, estas consecuencias no se analizaron en este estudio, por lo que se sugiere incluirlas en posteriores análisis.

En resumen, las infecciones oportunistas son enfermedades básicamente prevenibles, cuyo diagnóstico y tratamiento adecuados mejoran la supervivencia y el pronóstico de los pacientes $(3,21)$. Es necesario que los responsables de las decisiones en las instituciones prestadoras de servicios y en las empresas administradoras de planes de beneficios exploren los mecanismos para garantizar la continuidad del tratamiento y la atención integral y oportuna de las personas con HIV desde una perspectiva diferencial, ya que hay grupos poblacionales vulnerables con mayor predisposición a las infecciones oportunistas, como la población desplazada, los indígenas y las personas con problemas de acceso a la seguridad social o a los medicamentos.

Asimismo, se sugiere la implementación coordinada de programas con las instancias pertinentes que permitan a todas las personas con HIV acceder a un tratamiento médico de calidad (81), y que faciliten el apoyo social que necesitan ellas y sus cuidadores, incluidas consultas oportunas para el seguimiento de la enfermedad y la prevención de complicaciones clínicas que puedan llevar a una mayor demanda de servicios más complejos y costosos. También, es preciso estudiar con mayor profundidad la discapacidad permanente que pueden generar las infecciones oportunistas, con el fin de brindar una rehabilitación adecuada para sobrellevar la enfermedad y reincorporarse al medio social y productivo.

Una de las limitaciones del estudio fue la utilización de fuentes secundarias. Desde el 2008, la Cuenta de Alto Costo es el organismo encargado de recopilar, auditar y compilar la información nacional a partir de los registros generados por cada EPS $(37,82)$. Dicha información tiene, por lo menos, tres problemas. El primero es que limita la posibilidad de abordar otras variables y poblaciones de interés que contribuyan a una comprensión adecuada del fenómeno; el segundo está relacionado con la calidad de los datos, y el tercero está asociado con el anterior, por los potenciales conflictos de intereses y los dilemas que genera el hecho de que la Cuenta de Alto Costo esté conformada por las mismas EPS notificadoras. Por último, debe mencionarse que, aunque por ley dicha información debe ser pública y estar disponible para la investigación, el acceso fue limitado. 
El uso de fuentes secundarias circunscribe el estudio a variables, categorías y poblaciones preexistentes, excluyendo otras variables importantes para el análisis, como los tratamientos profilácticos, el seguimiento a los pacientes, los problemas con la transferencia de las historias clínicas entre los diferentes proveedores, así como la falta de un registro de las condiciones de discapacidad causadas por las infecciones oportunistas. Tampoco es posible establecer en series de tiempo la evolución epidemiológica de tales infecciones o el efecto en su prevalencia tras la incorporación del tratamiento antirretroviral.

La información disponible en esta base de datos solo permitió estimar la prevalencia de las infecciones en el grupo de personas con HIV afiliadas durante el periodo de estudio, es decir, cerca del 69,8\% (37.325) del total de 53.408 personas reportadas con HIV para ese mismo periodo en el país. La ausencia de datos sobre la población pobre no asegurada o sobre quienes por alguna razón no estaban afiliados, grupos que se consideran los de mayor vulnerabilidad en el país, impide conocer a fondo el problema y obliga a plantear nuevos estudios.

Si se parte del hecho de que esta población es estructuralmente más vulnerable y tiene menor acceso a los servicios de salud, es muy probable que la prevalencia de infecciones oportunistas exceda los valores aquí reportados. Los registros de fuente secundaria compilados por la Cuenta de Alto Costo no tienen la calidad deseable, a pesar de que esta función está delegada en dicha entidad. Además de la ausencia de variables importantes, los datos perdidos alcanzaron el $30 \%$ en algunas variables y se desconoce si los registros están duplicados, pues por razones éticas la base de datos no incluye la identificación personal, lo que permite afirmar que la calidad de los datos no es óptima. Para minimizar estos sesgos relacionados con la calidad de la información, en este estudio los valores atípicos o los datos perdidos se excluyeron del análisis.

Por último, el hecho de que sea la Cuenta de Alto Costo el organismo que compila los datos plantea varios inconvenientes: habría eventuales conflictos de intereses en la medida en que el reporte está directamente ligado con el reajuste de la unidad de pago por capitación en el sistema de salud actual, por lo tanto, es posible que en la información se subestimen o sobrestimen algunas variables de interés. Por otra parte, la base de datos de acceso público no permite establecer si los registros corresponden o no a un mismo paciente y, por lo tanto, la trazabilidad de la atención no es posible.

Estas limitaciones no invalidan los resultados del estudio, ya que, a pesar de los sesgos, fue posible determinar la prevalencia de las infecciones oportunistas en la era del tratamiento antirretroviral en poblaciones con HIV afiliadas al sistema de salud y reconocer los importantes problemas del sistema de información actual, los cuales exigen el mejoramiento urgente de la calidad de los registros y la inclusión en el análisis de toda la población, con el fin de adoptar medidas para el control de estas situaciones prevenibles e indeseables.

Para satisfacer estas exigencias y poder adelantar las investigaciones, se sugiere que sea la autoridad sanitaria la entidad encargada de exigir y garantizar la calidad de la información, de manera que, en un futuro, se logre el seguimiento de los pacientes y de su manejo clínico, independientemente de su estatus de afiliación al sistema de salud. 


\section{Agradecimientos}

Los autores agradecen a la Cuenta de Alto Costo, por el acceso a la base de datos; a la Línea de Investigación en Sistemas de Salud del Grupo de Investigación en Gestión y Políticas, por su apoyo en la consecución de recursos; a Anderson Bermon, por su apoyo en la revisión de los análisis, y a Erika Ríos, del Semillero de Investigación en Sistemas de Salud-Sissalud, por el apoyo en la búsqueda y revisión bibliográficas.

\section{Referencias}

1. Alves DN, Bresani-Salvi CC, Batista JDL, Ximenes RAA, Miranda-Filho DB, Melo HRL, et al. Use of the coding causes of death in HIV in the classification of deaths in Northeastern Brazil. Rev Saúde Pública. 2017;51:88. https://doi.org/10.11606/S1518-8787.2017051000124

2. Essomba N, Ngaba PG, Halle MP, Afane Y, Coppieters Y. Risk factors for mortality in patients with tuberculosis and HIV in Douala (Cameroon). Med Sante Trop. 2017;27:286-91. https://doi.org/10.1684/mst.2017.0713

3. Saavedra A, Campinha N, Hajjar M, Kenu E, Gillani FS, Obo A, et al. Causes of death and factors associated with early mortality of HIV-infected adults admitted to Korle-Bu Teaching Hospital. Pan Afr Med J. 2017;18:48. https://doi.org/10.11604/pamj.2017.27.48.8917

4. O'Brien KK, Bayoumi AM, Strike C, Young NL, Davis AM. Exploring disability from the perspective of adults living with HIV/AIDS: Development of a conceptual framework. Health Qual Life Outcomes. 2008;6:76. https://doi.org/10.1186/1477-7525-6-76

5. O'Brien KK, Bayoumi AM, Strike C, Young NL, King K, Davis AM. How do existing HIVspecific instruments measure up? Evaluating the ability of instruments to describe disability experienced by adults living with HIV. Health Qual Life Outcomes. 2010;8:88-98. https://doi org/10.1186/1477-7525-8-88

6. Parruti G, Manzoli L, Giansante A, D’Eramo C, Re V, Graziani R, et al. Occupational therapy for advanced HIV patients at a home care facility: A pilot study. AIDS Care. 2007;19:467-70. https://doi.org/10.1080/09540120601087103

7. Koole O, Colebunders R. Reducing mortality from HIV infection and tuberculosis. Lancet Infect Dis. 2011;11:494-5. https://doi.org/10.1016/S1473-3099(11)70094-9

8. Centers for Disease Control and Prevention. AIDS-defining conditions. Recommendations and reports. MMWR Recomm Rep. 2008;57:1-12.

9. Lim PL, Zhou J, Ditangco RA, Law MG, Sirisanthana T, Kumarasamy N, et al. Failure to prescribe pneumocystis prophylaxis is associated with increased mortality, even in the cART era: Results from the Treat Asia HIV observational database. J Int AIDS Soc. 2012;15:1. https://doi.org/10.1186/1758-2652-15-1

10. Coelho L, Veloso V, Grinsztejn B, Luz PM. Trends in overall opportunistic illnesses, Pneumocystis carinii pneumonia, cerebral toxoplasmosis and Mycobacterium avium complex incidence rates over the 30 years of the HIV epidemic: A systematic review. Braz $\mathrm{J}$ Infect Dis. 2014;18:196-210. https://doi.org/10.1016/j.bjid.2013.10.003

11. Ministerio de Salud y Protección Social. Guía para el manejo del VIH basada en la evidencia, Colombia. Modelo de gestión programática. Bogotá: Ministerio de Salud y Protección Social; 2012. p. 242.

12. ONUSIDA. Enfermedades oportunistas relacionadas con el VIH. Ginebra: UNAIDS; 1999. p. 1-12.

13. Ndinda C, Chimbwete C, McGrath N, Pool R, MDP Group. Community attitudes towards individuals living with HIV in rural KwaZulu-Natal, South Africa. AIDS Care. 2007;19:92-101. https://doi.org/10.1080/09540120600888378

14. Crowe S, Carlin J, Steward K, Ronald L, Hoy J. Predictive value of CD4 lymphocyte numbers for the development of opportunistic infections and malignancies in HIV-infected persons. J Acquir Immune Defic Syndr. 1991;4:770-6.

15. UNAIDS. Seguimiento de la declaración de compromiso sobre el VIH/Sida. Bogotá: Ministerio de Salud y Protección Social; 2012. p. 1-15.

16. Arrivillaga M, Springer A, Lopera M, Correa D, Useche B, Ross M. HIV/AIDS treatment adherence in economically better off women in Colombia. AIDS Care. 2012;24:929-35. https://doi.org/10.1080/09540121.2011.647678 
17. Soto LE, Herrera E. Guía de manejo antirretroviral de las personas con VIH. Recomendaciones para el tratamiento antirretroviral en adultos - versión bolsillo. Ginebra: Organización Mundial de la Salud; 2011. p. 1-25.

18. Brooks JT, Kaplan JE, Masur H. What's new in the 2009 US guidelines for prevention and treatment of opportunistic infections among adults and adolescents with HIV? Top HIV Med. 2009;17:109-14.

19. Limper AH, Adenis A, Le T, Harrison TS. Fungal infections in HIV/AIDS. Lancet Infect Dis. 2017;17:e334-e43. https://doi.org/10.1016/S1473-3099(17)30303-1

20. Iribarren JA, Rubio R, Aguirrebengoa K, Arribas JR, Baraia J, Gutiérrez F, et al. Executive summary: Prevention and treatment of opportunistic infections and other coinfections in HIV-infected patients: May 2015. Enferm Infecc Microbiol Clin. 2016;34:51723. https://doi.org/ 10.1016/i.eimc.2016.02.025

21. Bigliano $P$, Calcagno A, Lucchini A, Audagnotto $S$, Montrucchio $C$, Marinaro $L$, et al. The outcome of HIV-positive late presenters according to detectable CMV DNA and antiCMV treatment. Antivir Ther. 2018;23:451-6. doi: 10.3851/IMP3221

22. Álvarez MF, Restrepo CA, Hidrón A, Villa JP, Trompa IM, Restrepo L, et al. Hospitalization causes and outcomes in HIV patients in the late antiretroviral era in Colombia. AIDS Res Ther. 2017;14:60. https://doi.org/10.1186/s12981-017-0186-3

23. Cuenta de Alto Costo. Sistema de clasificación de las infecciones por VIH y esquemas de terapia antirretroviral de inicio. Revisión de evidencias con fines de reporte a la Cuenta de Alto Costo. 2011. Fecha de consulta: 28 de enero de 2018. Disponible en: https://cuentadealtocosto. org/site/images/Publicaciones/CLASIFICACION Y TAR PRIMERA LINEA.pdf

24. Pal J, Karmakar PS, Ray A, Saha S, Roy K, Talukdar A, et al. Opportunistic infections of central nervous system in AIDS. J Indian Med Assoc. 2009;107:446-9.

25. Spudich SS, Ances BM. Neurologic complications of HIV infection: Highlights from the 2013 Conference on Retroviruses and Opportunistic Infections. Top Antivir Med. 2013;21:100-8.

26. Gangaputra S, Drye L, Vaidya V, Thorne JE, Jabs DA, Lyon AT. Non-cytomegalovirus ocular opportunistic infections in patients with acquired immunodeficiency syndrome. Am J Ophthalmol. 2013;155:206-12. https://doi.org/10.1016/j.ajo.2012.07.019

27. Abdollahi A, Mohraz M, Rasoulinejad M, Shariati M, Kheirandish P, Abdollahi M, et al. Retinitis due to opportunistic infections in Iranian HIV infected patients. Acta Med Iran. 2013;51:711-4

28. Liu L, Zheng Y, Lu H. Development of primary central nervous system lymphoma in an HIV infected patient after multiple opportunistic infections. Int J STD AIDS. 2012;23:41-4. https:// doi.org/10.1258/ijsa.2009.009214

29. Campo LE, Sifuentes J. Infecciones oportunistas en el síndrome de inmunodeficiencia adquirida: la historia en México a 20 años del inicio de la epidemia. Rev Invest Clin. 2004;56:169-80.

30. Contreras J. Manifestaciones pulmonares en pacientes con sida. 2013. Fecha de consulta: 20 de febrero de 2018. Disponible en: http://es.slideshare.net/kgonzlez3/manifestacionespulmonares-en-pacientes-con-sida

31. Tan IL, Smith BR, von Geldern G, Mateen FJ, McArthur JC. HIV-associated opportunistic infections of the CNS. Lancet Neurol. 2012;11:605-17. https:/doi.org/10.1016/S14744422(12)70098-4

32. Juliao O, Corredor A, Moreno G. Estudio Nacional de Salud: toxoplasmosis en Colombia Bogotá: Instituto Nacional de Salud; 1998.

33. Lizarazo J, Castro F, De Arco M, Chaves Ó, Peña Y. Infecciones oportunistas del sistema nervioso central en pacientes con VIH atendidos en el Hospital Universitario Erasmo Meoz, Cúcuta, 1995-2005. Infectio. 2006;10:226-321.

34. Castiblanco CA, Ribón W .Coinfección de tuberculosis en pacientes con VIH/SIDA: un análisis según las fuentes de información en Colombia. Infectio. 2006;10:232-42.

35. Botero JH, Montoya MN, Vanegas AL, Díaz A, Martínez LN, Bornay FJ, et al. Frecuencia de microsporidiosis intestinal en pacientes positivos para VIH mediante las técnicas de Gram cromotropo rápido y PCR. Biomédica. 2004;24:375-84. https://doi.org/10.7705/ biomedica.v24i4.1287

36. Navarro L, Silva AJ, Botero JH, Montoya MN, Aguila C, Bornay FJ. Cryptosporidiosis in HIV-positive patients from Medellín, Colombia. J Eukaryot Microbiol. 2006;53:37-9. https:// doi.org/10.1111/j.1550-7408.2006.00167.x 
37. Ministerio de la Protección Social. Resolución 4725. Por la cual se define la periodicidad, la forma y el contenido de la información que deben reportar las entidades promotoras de salud y las demás entidades obligadas a compensar a la Cuenta de Alto Costo, relacionada con la infección por el virus de inmunodeficiencia humana $(\mathrm{VIH})$ y el síndrome de inmunodeficiencia adquirida (sida). Bogotá: Ministerio de Salud y Protección Social; 2011.

38. Cuenta de Alto Costo. Instructivo para el reporte de información según Resolución 4725/11 y resolución 783/2012. Medición 31 de enero 2013. Bogotá: Cuenta de Alto Costo; 2013. p. 1-23.

39. Centers for Disease Control and Prevention. Revised classification system for HIV infection and expanded surveillance case definition for AIDS among adolescents and adults. MMWR Recomm Rep. 1993;18:1-19.

40. World Health Organization. WHO case definitions of HIV for surveillance and revised clinical staging and immunological classification of HIV-related disease in adults and children. 2007. Fecha de consulta: 19 de agosto de 2017. Disponible en: http://www.who.int/ iris/handle/10665/43699

41. Ministerio de Salud. Resolución № 008430 . Por la cual se establecen las normas científicas, técnicas y administrativas para la investigación en salud. Santafé de Bogotá: INVIMA; 1993. p. 1-21.

42. Ministerio de Salud y Protección Social. Resumen de situación de la epidemia por VIH/SIDA en Colombia 1983 a 2011. 2012. Fecha de consulta: 19 de abril 19 de 2016. Disponible en: https://www.minsalud.gov.co/salud/Documents/observatorio_vih/ documentos/monitoreo evaluacion/1 vigilancia salud publica/a situacion epidimiologica/ RESUMEN\%20EPIDEMIA\%20VIIH\%20FINAL\%2021\%20mayo 2012.pdf

43. Hu C, Huang Y, Su J, Wang M, Zhou Q, Zhu B. The prevalence and isolated subtypes of BK polyomavirus reactivation among patients infected with human immunodeficiency virus-1 in southeastern China. Arch Virol. 2018;163:1463-8. https://doi.org/10.1007/s00705-018-3724-y

44. Parra CM, Valderrama SL, Cortés G, Garzón JR, Ariza BE, Morio F, et al. First report of sporadic cases of Candida auris in Colombia. Int J Infect Dis. 2018;69:63-7. https://doi org/10.1016/j.jijid.2018.01.034

45. Smith N, Sehring M, Chambers J, Patel P. Perspectives on non-neoformans cryptococcal opportunistic infections. J Community Hosp Intern Med Perspect. 2017;7:214-7. https://doi. org/10.1080/20009666.2017.1350087

46. Iroezindu MO. Disparities in the magnitude of human immunodeficiency virus-related opportunistic infections between high and low/middle-income countries: Is highly active antiretroviral therapy changing the trend? Ann Med Health Sci Res. 2016;6:4-18. https://doi. org/10.4103/2141-9248.180234

47. Lopera MM, Martínez J, Ray T. Acceso de las personas con VIH al sistema de salud colombiano y sus costos relacionados desde una perspectiva individual y familiar. Rev. Gerenc. Polit. Salud. 2011;10:81-96.

48. Lopera M, Einarson T, Bula J. Out-of-pocket expenditures and coping strategies for people living with HIV: Bogotá, Colombia, 2009. AIDS Care. 2011;23:1602-8. https://doi.org/10.108 0/09540121.2011.57993848

49. Thoden J, Potthoff A, Bogner JR, Brockmeyer NH, Esser S, GrabmeierK, et al. Therapy and prophylaxis of opportunistic infections in HIV-infected patients: A guideline by the German and Austrian AIDS societies (DAIG/OAG) (AWMF 055/066). Infection. 2013;41(Supl.2):91-115. https://doi.org/10.1007/s15010-013-0504-1

50. Buchacz K, Lau B, Jing Y, Bosch R, Abraham AG, Gill MJ, et al. Incidence of AIDSdefining opportunistic infections in a multicohort analysis of HIV-infected persons in the United States and Canada, 2000-2010. J Infect Dis. 2016;214:862-72. https://doi. org/10.1093/infdis/jiw085

51. Akinyemi JO, Ogunbosi BO, Fayemiwo AS, Adesina OA, Obaro M, Kuti MA, et al. Demographic and epidemiological characteristics of HIV opportunistic infections among older adults in Nigeria. Afr Health Sci. 2017;17:315-21. https://doi.org/10.4314/ahs.v17i2.4

52. Shenoy N, Ramapuram JT, Shenoy A, Ahmed J, Srikant N. Incidence of opportunistic infections among HIV-positive adults on highly active antiretroviral therapy in a teaching hospital, India: Prospective study. J Int Assoc Provid AIDS Care. 2017;16:309-11. https://doi. org/10.1177/2325957416686192

53. Coelho L, Cardoso SW, Amancio RT, Moreira RI, Campos DP, Veloso VG, et al. Trends in AIDS-defining opportunistic illnesses incidence over 25 years in Rio de Janeiro, Brazil. Plos One. 2014;9:e98666. https://doi.org/10.1371/journal.pone.0098666 
54. Ekwaru J, Cambell J, Malamba S, Moore D, Were W, Mermin J. The effect of opportunistic illness on HIV RNA viral load and CD4+ T cell count among HIV-positive adults taking antiretroviral therapy. J Int AIDS Soc. 2013;1:17355. https://doi.org/10.7448/ IAS.16.1.17355

55. Nobre V, Braga E, Rayes A, Serufo JC, Godoy P, Nunes N, et al. Opportunistic infections in patients with aids admitted to an university hospital of the Southeast of Brazil. Rev Inst Med Trop Sao Paulo. 2003;45:69-74. https://doi.org/10.1590/S0036-46652003000200003

56. Gangcuangco LMA, Sawada I, Tsuchiya N, Do CD, Pham TT, Rojanawiwat A, et al. Regional differences in the prevalence of major opportunistic infections among antiretroviralnaive human immunodeficiency virus patients in Japan, Northern Thailand, Northern Vietnam, and the Philippines. Am J Trop Med Hyg. 2017;97:49-56. https://doi.org/10.4269/ ajtmh.16-0783

57. World Health Organization. The Global Plan to Stop TB 2011-2015. In: Transforming the Fight. Towards elimination of tuberculosis. Geneva: World Health Organization; 2011. p. 1-101.

58. Luft BJ, Hafner R, Korzun A, Leport C, Antoniskis D, Bosler EM, et al. Toxoplasmic encephalitis in patients with the acquired immunodeficiency syndrome. Members of the ACTG 077p/ANRS 009 Study Team. N Engl J Med. 1993;329:995-1000.https://doi. org/10.1056/NEJM199309303291403

59. Rey MF, Mary C, Sanguinetti D, Ranque S, Bartoli C, L'Ollivier C. Successful treatment of pulmonary and cerebral toxoplasmosis associated with Pneumocystis pneumonia in an HIV patient. Diseases. 2017;5. https://doi.org/10.3390/diseases5040035

60. Wang ZD, Liu Q, Liu HH, Li S, Zhang L, Zhao YK, et al. Prevalence of Cryptosporidium, microsporidia and Isospora infection in HIV-infected people: A global systematic review and meta-analysis. Parasit Vectors. 2018;11:28. https://doi.org/10.1186/s13071-017-2558-X

61. Crowell TA, Lyall H, Malatinkova E, Bhagani S, Hsu D, Colby DJ, et al. Highlights from the 24th Conference on Retroviruses and Opportunistic Infections: 13-16 February 2017, Seattle, Washington, USA. J Virus Erad. 2017;3:101-8.

62. Yang R, Zhang H, Xiong Y, Gui X, Zhang Y, Deng L, et al. Molecular diagnosis of central nervous system opportunistic infections and mortality in HIV-infected adults in Central China. AIDS Res Ther. 2017;2:1-24. https://doi.org/10.1186/s12981-017-0150-2

63. World Health Organization. WHO Region of the Americas: Colombia statistics summary (2002 - present) - Geneva: World Health Organization; 2011. Fecha de consulta: 12 de junio de 2017. Disponible en: http://apps.who.int/gho/data/node.country.country-COL

64. Senya C, Mehta A, Harwell JI, Pugatch D, Flanigan T, Mayer KH. Spectrum of opportunistic infections in hospitalized HIV-infected patients in Phnom Penh, Cambodia. Int J STD AIDS. 2003;14:411-6. https://doi.org/10.1258/095646203765371312

65. Crabtree B, Caro Y, Shepherd BE, Grinsztejn B, Wolff M, Cortés CP, et al. Time to HAART initiation after diagnosis and treatment of opportunistic infections in patients with AIDS in Latin America. PLoS One. 2016;11:e0153921. https://doi.org/10.1371/journal.pone.0153921

66. UNAIDS. Global Report. Geneva: WHO; 2013. Fecha de consulta: 5 de mayo de 2017. Disponible en: http://data.unaids.org/pub/FactSheet/2009/20091124 FS global es.pdf

67. González A, Tobón MÁ. Infecciones micóticas oportunistas en pacientes con VIH/SIDA. Infectio. 2006;10:279-88.

68. ONUSIDA. Comunicado de prensa. Ginebra: ONUSIDA; 2013. Fecha de consulta: 5 de mayo de 2017. Disponible en: http://www.unaids.org/es/resources/presscentre/ pressreleaseandstatementarchive/2013/september/20130923prunga

69. Chaiwarith R, Praparattanapan J, Nuntachit N, Kotarathitithum W, Supparatpinyo K. Discontinuation of primary and secondary prophylaxis for opportunistic infections in HIVinfected patients who had CD4+ cell count $<200$ cells/mm (3) but undetectable plasma HIV1 RNA: An open-label randomized controlled trial. AIDS Patient Care STDS. 2013;27:71-6. https://doi.org/10.1089/apc.2012.0303

70. Karo B, Krause G, Castell S, Kollan C, Hamouda O, Haas W, et al. Immunological recovery in tuberculosis/HIV co-infected patients on antiretroviral therapy: Implication for tuberculosis preventive therapy. BMC Infect Dis. 2017;17:517. https://doi.org/10.1186/ s12879-017-2627-y

71. Hakim J, Musiime V, Szubert AJ, Mallewa J, Siika A, Agutu C, et al. Enhanced prophylaxis plus antiretroviral therapy for advanced HIV infection in Africa. N Engl J Med. 2017;377:233-45. https://doi.org/1010.1056/NEJMoa1615822 
72. Chastain DB, Franco C, Stover KR. Addressing antiretroviral therapy-associated drugdrug interactions in patients requiring treatment for opportunistic infections in low-income and resource-limited settings. J Clin Pharmacol. 2017;57:1387-99. https://doi.org/10.1002/ jcph.978

73. Gascón MR, Vidal JE, Mazzaro YM, Smid J, Marcusso RM, Capitao CG, et al. Neuropsychological assessment of 412 HIV-infected individuals in Sao Paulo, Brazil. AIDS Patient Care STDS. 2018;32:1-8. https://doi.org/10.1089/apc.2017.0202

74. Sosa R, Fernández C, Varona G, Echevarría Y. Una visión clínica sobre las enfermedades oportunistas y el SIDA. Rev Méd Electrón. 2009;31.

75. Cuenta de Alto Costo. Distribución de población por aseguradora-régimen y sexo. Bogotá: Cuenta de Alto Costo; 2012.

76. Álvarez M, de León J, Herrera B. Manifestaciones neurológicas en el paciente con SIDA. Rev Med Electrón. 2009;31:1-5.

77. Feroze KB, Wang J. Ocular manifestations of HIV infection. 2017. Fecha de consulta: 19 de febrero de 2018. Disponible en: https://emedicine.medscape.com/article/1216172overview

78. Sumonu T, Imarhiagbe F, Owolabi L, Ogunrin O, Komolafe M, llesanmi O. Cognitive functions in newly diagnosed patients with HIV infection in a tertiary health facility: Assessment using community screening interview for dementia. eNeurologicalSci. 2017;9:813. https://doi.org/10.1016/j.ensci.2017.10.001

79. Hassan R, Chinappa T, Jeena L, Visser L, Naidoo K. Cytomegalovirus retinitis and HIV: Case reviews from KwaZulu-Natal Province, South Africa. S Afr Med J. 2017;107:843-46. https://doi.org/10.7196/SAMJ.2017.v107i10.12740

80. Kolson D. Neurologic complications of HIV infection in the era of antiretroviral. Top Antivir Med. 2017;25:97-101

81. Sullivan PS, Denniston M, McNaghten A, Buskin SE, Broyles ST, Mokotoff ED. Use of a population-based survey to determine incidence of AIDS-defining opportunistic illnesses among HIV-positive persons receiving medical care in the United States. AIDS Res Ther. 2007;4:17. https://doi.org/ 10.1186/1742-6405-4-17

82. Ministerio de Salud y Protección Social. Resolución 783. Por la cual se efectúan unas modificaciones y se corrigen unos yerros al Anexo Técnico de la Resolución 00004725 de 2011. Bogotá: Ministerio de Salud y Protección Social; 2012. 